\title{
Influência da inoculação de rizóbios sobre a germinação e o vigor de plântulas de alface
}

\author{
Influence of rhizobial inoculation on seedling vigor and germination of lettuce
}

\author{
Gilson Schlindwein $^{\mathrm{I}}$ Luciano Kayser Vargas $^{{ }^{*}}$ Bruno Brito Lisboa $^{\mathrm{I}}$ Augusto Cruz Azambuja ${ }^{\mathrm{I}}$ \\ Camille Eichelberger Granada ${ }^{\text {II }}$ Naiana Cristine GabiattiI ${ }^{\text {F }}$ Felipe Prates ${ }^{\text {II }}$ Raquel Stumpf ${ }^{\text {II }}$
}

\section{RESUMO}

Os rizóbios, conhecidos por sua capacidade de fixar $N_{2}$ em associação com leguminosas, também se mostram capazes de promover o crescimento de não-leguminosas, especialmente pela produção de ácido indol-acético (AIA). Neste trabalho, objetivou-se selecionar rizóbios produtores de AIA e avaliar o efeito de diferentes concentrações deste fitormônio sobre a germinação e o desenvolvimento inicial de plântulas de alface. Foram selecionados quatro isolados de Bradyrhizobium sp. e um isolado de Rhizobium leguminosarum biovar trifolii, os quais foram crescidos por quatro dias em meio levedura-manitol enriquecido com triptofano. Após esse periodo, avaliou-se a produção de AIA e procedeu-se à inoculação de sementes de alface com os isolados. O isolado $T V-13$, de R. leguminosarum biovar trifolii produziu 171,1 $\mu \mathrm{g}$ $m L^{-1}$ de AIA, causando prejuizos para o desenvolvimento das plântulas de alface. Por outro lado, os isolados de

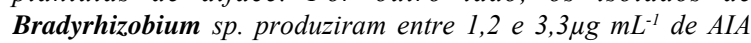
e aumentaram o vigor das plântulas em relação ao tratamento sem inoculação com rizóbios. Para verificar se essas diferenças foram decorrentes das concentrações de AIA, foram realizados mais dois experimentos, nos quais as sementes foram embebidas em culturas de TV-13 com ou sem a presença de triptofano ou em doses crescentes de AIA sintético. O isolado TV-13 crescido na presença de triptofano causou danos progressivos sobre o desenvolvimento das plântulas de alface, o que não ocorreu na ausência de triptofano. Também foi verificado um retardo na germinação das sementes quando submetidas a altas concentrações de AIA sintético. Os resultados indicam a influência do AIA sobre os parâmetros de germinação, de modo que a inoculação de sementes de alface com rizóbios que produzem baixas quantidades de AIA é uma prática recomendável.
Palavras-chave: $\begin{aligned} & \text { Rhizobium, ácido indol-acético, } \\ & \text { rizobactérias, promoção de crescimento. }\end{aligned}$

\section{ABSTRACT}

Rhizobia are known by their ability to fix nitrogen in symbiosis with legumes, but they are also capable of promote the growth of non-legume, mainly due to indoleacetic acid production (IAA). In this research, it was aimed to select rhizobia producers of IAA and evaluate the effect of different levels of this hormone over the germination and initial development of lettuce seedlings. Four isolates of Bradyrhizobium sp. and one isolate of Rhizobium leguminosarum biovar trifolii were grown during four days in yeast manitol medium enriched with tryptophan. After that period, the production of IAA was evaluated and the isolates were inoculated in lettuce seeds. The isolate $T V-13$, of $\boldsymbol{R}$. leguminosarum biovar trifolii, produced 171.1 $\mu \mathrm{g} \mathrm{mL}^{-1}$ of IAA, causing damages to lettuce seedlings. On other hand, Bradyrhizobium sp. isolates produced between 1.2

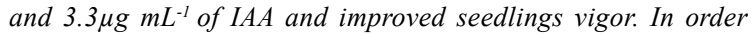
to verify if these results were due to IAA concentrations, other two assays were carried out, in which lettuce seeds were imbibed in TV-13 cultures with or without tryptophan or in increasing dosages of synthetic IAA. The isolate TV-13 grown in the presence of tryptophan caused progressive damages to lettuce seedlings development, fact that did not occur in the absence of tryptophan. It was also verified a delay in germination of seeds exposed to high levels of synthetic IAA. The results show the influence of IAA on germination parameters, so that the inoculation of lettuce seeds with rhizobia that produce low amounts of IAA is a recommended practice.

Key words: Rhizobium, indoleacetic acid, rhizobacteria, growth promotion.

'Fundação Estadual de Pesquisa Agropecuária (FEPAGRO). Rua Gonçalves Dias, 570, 90130-060, Porto Alegre, RS, Brasil. E-mail: luciano@fepagro.rs.gov.br. *Autor para correspondência.

"Curso de Engenharia de Bioprocessos e Biotecnologia, Universidade Estadual do Rio Grande do Sul (UERGS), Porto Alegre, RS, Brasil.

${ }^{\text {IIIC }}$ Cursode Agronomia, Universidade Federal do Rio Grande do Sul (UFRGS), Porto Alegre, RS, Brasil. 


\section{INTRODUÇÃO}

Durante o ciclo de vida de uma planta, as fases iniciais do desenvolvimento são consideradas cruciais, uma vez que, entre a germinação da semente e o estabelecimento da plântula, ocorrem as maiores taxas de mortalidade (HARPER, 1977). Além disso, o vigor da plântula é um fator crítico quando a competição por luz, nutrientes, ar e água começa a se tornar mais acentuada (BISWAS et al., 2000). Assim, a qualidade fisiológica das sementes e o vigor das plântulas são fatores decisivos no sucesso produtivo de uma determinada cultura agrícola.

A taxa de germinação e o vigor das plântulas, por sua vez, dependem tanto de fatores genéticos inerentes à semente, quanto de práticas culturais que podem alterá-las. Dentre as práticas culturais, a inoculação com microrganismos benéficos tem recebido especial atenção nos últimos anos por se tratar de uma alternativa de baixo custo e ambientalmente amigável, constituindo-se em uma ferramenta importante para o estabelecimento de sistemas agrícolas sustentáveis. Os benefícios da inoculação de microrganismos em sementes podem ser indiretos, por meio da supressão de patógenos (SOTTERO et al., 2006), por exemplo, ou diretos, por meio do aumento da absorção de nutrientes ou de alterações no balanço hormonal da planta (AHMAD et al., 2005).

A inoculação de rizóbios em culturas leguminosas é provavelmente a prática de emprego de bactérias na agricultura mais difundida, aproveitando a capacidade dessas bactérias fixarem nitrogênio em associação com plantas daquela família. No entanto, nos últimos anos, tem se verificado que essas bactérias também possuem a capacidade de atuar como promotoras de crescimento vegetal em nãoleguminosas, atuando por meio de diversos fatores de promoção de crescimento de plantas. Dentre esses fatores, a produção de ácido indol-acético (AIA) tem sido apontada como o mais importante (BISWAS et al., 2000; HAFEEZ et al., 2004; NOEL et al., 1996). O AIA, fitormônio pertencente ao grupo das auxinas, atua principalmente na formação de raízes laterais e de pêlos radiculares que aumentam a absorção de nutrientes pela planta (BISWAS et al., 2000). Nas fases iniciais das culturas, há relatos de que a inoculação com rizóbios produtores de AIA pode aumentar o vigor de plântulas de arroz (BISWAS et al. 2000) e a emergência de plântulas de algodão (HAFEEZ et al., 2004).

O presente trabalho teve como objetivos avaliar a ação de rizóbios sobre sementes de alface, uma planta não-leguminosa, e relacionar essa ação com a produção de AIA pelos rizóbios.

\section{MATERIAL E MÉTODOS}

Experimento 1 - Avaliação de rizóbios produtores de AIA na germinação e no desenvolvimento de plântulas de alface. Neste experimento, foram utilizados quatro isolados de Bradyrhizobium sp noduladores de acácia-negra (T64, T6-12, V-10 e C3) e um de Rhizobium leguminosarum biovar trifolli, (TV-13) nodulador de trevo-vesiculoso, todos pertencentes à coleção do Laboratório de Fitopatologia da FEPAGRO. As culturas foram crescidas em meio líquido levedura manitol (LM) enriquecido com triptofano - precursor do AIA - em incubadora com agitação orbital a 100 RPM por quatro dias.

Para a quantificação da produção de AIA em meio de cultura, utilizou-se o procedimento descrito por ASGHAR et al. (2002). Após as culturas terem sido centrifugadas por $5 \mathrm{~min}$ a $10.000 \mathrm{RPM}$, o sobrenadante das culturas foi coletado e misturado com o reagente

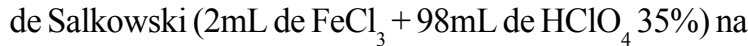
proporção de 1,5:1. $\mathrm{O} \mathrm{HClO}_{4}$ oxida o AIA e, na presença de $\mathrm{FeCl}_{3}$, produz uma cor avermelhada cuja intensidade é proporcional à quantidade de AIA na amostra. Depois de 30 minutos, foi feita a leitura das amostras em espectrofotômetro a $535 \mathrm{~nm}$. Para a determinação de AIA nas amostras, foi feita uma curva padrão com concentrações conhecidas da forma sintética do hormônio $\left(0,2 \mu \mathrm{g} \mathrm{mL}^{-1}, 5,6 \mu \mathrm{g} \mathrm{mL}^{-1}, 11,25 \mu \mathrm{g} \mathrm{mL}^{-1}, 22,5 \mu \mathrm{g}\right.$ $\mathrm{mL}^{-1}$ e $45 \mu \mathrm{g} \mathrm{mL}^{-1}$ ), cujas leituras foram a base para calcular a concentração do AIA nas amostras.

$\mathrm{Na}$ avaliação do efeito dos rizóbios sobre a germinação de alface, foram utilizadas sementes submetidas previamente à assepsia com álcool $70 \%$ (1 min) e hipoclorito de sódio ( $2 \mathrm{~min}$ ), seguida de cinco lavagens com água esterilizada. Os testes foram conduzidos em gerboxes com quatro repetições com 50 sementes cada, colocadas em papel substrato germitest umedecido com $16 \mathrm{~mL}$ de meio de cultura LM estéril (controle) ou contendo um dos quatro isolados de Bradyrhizobium sp. (T6-12; V10; T6-4 e C3) ou de R. leguminosarum biovar trifolii (TV-13), compondo seis tratamentos. Após a montagem dos testes, as sementes foram colocadas em temperatura de $5^{\circ} \mathrm{C}$ por três dias (choque frio) e em seguida em germinadores com luz constante e temperatura de $20^{\circ} \mathrm{C}$, conforme regras internacionais para análise de sementes (ISTA, 1996)

De modo a avaliar a germinação, foram utilizados como parâmetros a porcentagem final de sementes germinadas $(\mathrm{G} \%)$, as porcentagens de plântulas normais (N\%) e o índice de velocidade de germinação com base nas sementes germinadas

Ciência Rural, v.38, n.3, mai-jun, 2008. 
(IVG\%), calculado pela soma do número de sementes germinadas a cada dia, e dividido pelo respectivo número de dias transcorridos a partir de semeadura, conforme MAGUIRE (1962). Os dados foram obtidos a partir de contagens diárias após a emergência da plântula. Ao final de sete dias, o teste de germinação foi concluído. Então, foram retiradas, de cada unidade experimental, dez plântulas. Essas plântulas foram avaliadas quanto à massa seca (MS) e ao comprimento, em $\mathrm{cm}$, da raiz (RA) e da parte aérea (PA).

Experimento 2 - Relação entre a presença de triptofano e o isolado TV-13 sobre a germinação e o crescimento de plântulas de alface. Este experimento teve por objetivo verificar se as alterações na germinação de sementes de alface inoculadas com o isolado TV-13, observadas no experimento anterior, foram decorrentes da presença do isolado, da presença do triptofano no meio de cultura ou da produção de AIA pelo isolado. As sementes foram submetidas aos seguintes tratamentos: água destilada (controle), meio LM sem triptofano, TV-13 crescido em meio LM sem triptofano, meio LM com triptofano, TV-13 crescido em meio LM com triptofano e TV-13 crescido em meio LM com triptofano esterilizado em autoclave. Da mesma forma que nos ensaios anteriores, foram avaliados os índices de germinação e o crescimento da raiz e da parte aérea das plântulas de alface.

Experimento 3 - Efeito de diferentes concentrações de AIA sintético sobre a germinação e o desenvolvimento de plântulas de alface. Para avaliar a influência da concentração de AIA sintético sobre a germinação e a emergência de plântulas de alface, as sementes foram tratadas com doses crescentes de AIA. Foram usadas as concentrações de AIA de $2,5 \mu \mathrm{g} \mathrm{mL}^{-1}$, $25 \mu \mathrm{g} \mathrm{mL}^{-1}, 50 \mu \mathrm{g} \mathrm{mL}^{-1}$ e $100 \mu \mathrm{g} \mathrm{mL}^{-1}$, além de um controle sem AIA. Para avaliar a germinação e o desenvolvimento das plântulas, mantiveram-se os procedimentos citados anteriormente.

Os três experimentos foram conduzidos nos Laboratórios de Fitopatologia e de Tecnologia de Sementes da FEPAGRO, em Porto Alegre. Em cada um dos experimentos, a comparação entre os tratamentos foi feita por meio da análise de variância $(a=0,05)$. Em caso de significância estatística, aplicou-se o teste de Tukey para separação das médias obtidas entre os diferentes tratamentos testados. As análises estatísticas foram realizadas utilizando-se o pacote estatístico Sigmastat, versão 2.0 (SPSS Inc.).

\section{RESULTADOS E DISCUSSÃO}

Os rizóbios testados apresentaram diferenças marcantes quanto à capacidade de produzir
AIA(Tabela 1). O isolado TV-13 produziu quantidades de AIA cerca de 100 vezes maiores do que as produzidas pelos demais isolados testados. $\mathrm{Na}$ comparação dos cinco isolados, não foi constatada diferença significativa entre os quatro isolados de Bradyrhizobium. Porém, quando se desconsidera o isolado TV-13 e comparam-se apenas as estirpes de Bradyrhizobium, T6-4 se destaca, com o dobro da concentração de AIA produzida pelos demais.

A avaliação dos parâmetros de desenvolvimento de plântulas mostrou diferenças significativas entre os isolados testados (Tabela 2). A inoculação com os isolados de Bradyrhizobium sp. resultou em um efeito positivo nas taxas que avaliam o desenvolvimento das plântulas, com valores significativamente superiores nos índices de porcentagem de plântulas normais (N\%), crescimento de raiz e parte aérea. Dentre esses isolados, destaca-se o T6-4 com os maiores valores obtidos de N\% e de crescimento de raiz. Por outro lado, as sementes inoculadas com o isolado R. leguminosarum biovar trifolii TV-13 diferiram das demais por não desenvolverem plântulas normais, sem emissão de radícula e abertura precoce de cotilédones, além de apresentarem taxas de crescimento com índices reduzidos de maneira drástica (Figura 1). De acordo com BISWAS et al. (2000), o AIA, assim como outros fitormônios, estimulam o crescimento de plantas apenas dentro de uma faixa estreita de concentração. Fora dessa faixa benéfica, as concentrações mais baixas são ineficazes e as mais elevadas, são tóxicas. AHMAD et al. (2005), trabalhando com isolados de Azotobacter produtores de AIA, observaram um aumento no elongamento radicular de plântulas de Sesbania aculeata em concentrações de AIA entre $4,40 \mu \mathrm{g} \mathrm{mL}^{-1} \mathrm{e}$ $24,80 \mu \mathrm{g} \mathrm{mL}^{-1} \mathrm{e}$, em plântulas de Vigna radiata, entre $4,40 \mu \mathrm{g} \mathrm{mL}^{-1}$ e $14,36 \mu \mathrm{g} \mathrm{mL}^{-1}$. Por sua vez, BARAZANI \& FRIEDMAN, (1999) constataram que rizobactérias com ação deletéria sobre plântulas de alface excretaram concentrações de AIA em torno de $13,5 \mu \mathrm{g} \mathrm{mL} \mathrm{m}^{-1}$, enquanto as benéficas excretaram pouco menos de $3 \mu \mathrm{g}$

Tabela 1 - Quantidades de AIA produzidas por rizóbios em meio LM enriquecido com triptofano.

\begin{tabular}{lc}
\hline Isolado & AIA $\left(\mu \mathrm{g} \mathrm{mL}^{-1}\right)$ \\
\hline TV-13 & $171,1 \mathrm{a}$ \\
T6-4 & $3,3 \mathrm{~b}$ \\
T6-12 & $1,8 \mathrm{~b}$ \\
C-3 & $1,6 \mathrm{~b}$ \\
$\mathrm{~V}-10$ & $1,2 \mathrm{~b}$ \\
\hline
\end{tabular}

Médias seguidas de mesma letra não diferem significativamente entre si pelo teste de Tukey $(\mathrm{P}>0,05)$. 
Tabela 2 - Influência de culturas com diferentes isolados de rizóbios produtores de AIA sobre a germinação e o crescimento de plântulas de alface.

\begin{tabular}{|c|c|c|c|c|c|c|}
\hline \multirow{2}{*}{ Tratamento } & \multicolumn{3}{|c|}{ Germinação } & \multicolumn{2}{|c|}{ Comprimento } & \multirow[t]{2}{*}{ Massa seca } \\
\hline & Final & Normais & IVG & Parte aérea & Raiz & \\
\hline & \multicolumn{3}{|c|}{ 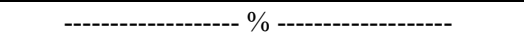 } & \multicolumn{2}{|c|}{------------ (cm) ------------ } & --- (g) --- \\
\hline Controle & $94,5 \mathrm{a}$ & $55,50 \mathrm{ab}$ & $17,40 \mathrm{a}$ & $2,19 \mathrm{c}$ & $0,48 \mathrm{~b}$ & 2,63 a \\
\hline T6-12 & $89,0 \mathrm{a}$ & $49,00 \mathrm{~b}$ & $17,10 \mathrm{a}$ & $4,65 \mathrm{a}$ & $2,95 \mathrm{a}$ & $2,63 \mathrm{a}$ \\
\hline V10 & $95,0 \mathrm{a}$ & $52,50 \mathrm{ab}$ & $17,40 \mathrm{a}$ & $4,45 \mathrm{ab}$ & $3,03 \mathrm{a}$ & $2,61 \mathrm{a}$ \\
\hline T6-4 & $92,5 \mathrm{a}$ & $65,50 \mathrm{a}$ & $17,20 \mathrm{a}$ & $4,48 \mathrm{ab}$ & $3,28 \mathrm{a}$ & $2,62 \mathrm{a}$ \\
\hline $\mathrm{C} 3$ & $96,5 \mathrm{a}$ & $59,50 \mathrm{ab}$ & $17,70 \mathrm{a}$ & $4,17 \mathrm{~b}$ & $2,70 \mathrm{a}$ & $2,62 \mathrm{a}$ \\
\hline TV -13 & $84,0 \mathrm{a}$ & $0,00 \mathrm{c}$ & $15,50 \mathrm{a}$ & $1,13 \mathrm{~d}$ & $0,00 \mathrm{~b}$ & $2,59 \mathrm{a}$ \\
\hline
\end{tabular}

Médias seguidas de mesma letra dentro das colunas não diferem significativamente entre si pelo teste de Tukey $(\mathrm{P}>0,05)$.

$\mathrm{mL}^{-1}$. Em razão de seu efeito estimulatório sobre as sementes de alface, as quantidades de AIA produzidas pelos isolados de Bradyrhizobium sp. parecem estar dentro da faixa benéfica de concentração apontada pelos autores. O isolado T6-4 tem uma maior produção de $\operatorname{AIA}\left(3,3 \mu \mathrm{g} \mathrm{mL}^{-1}\right)$, mas que ainda ficaria dentro dessa faixa, o que resultou em maior benefício para as plântulas.

Alguns estudos com feijão (BIALEK et al., 1992; BIALEK \& COHEN, 1992) mostraram que a biossíntese de AIA a partir do triptofano é o principal recurso de auxina durante a germinação e o

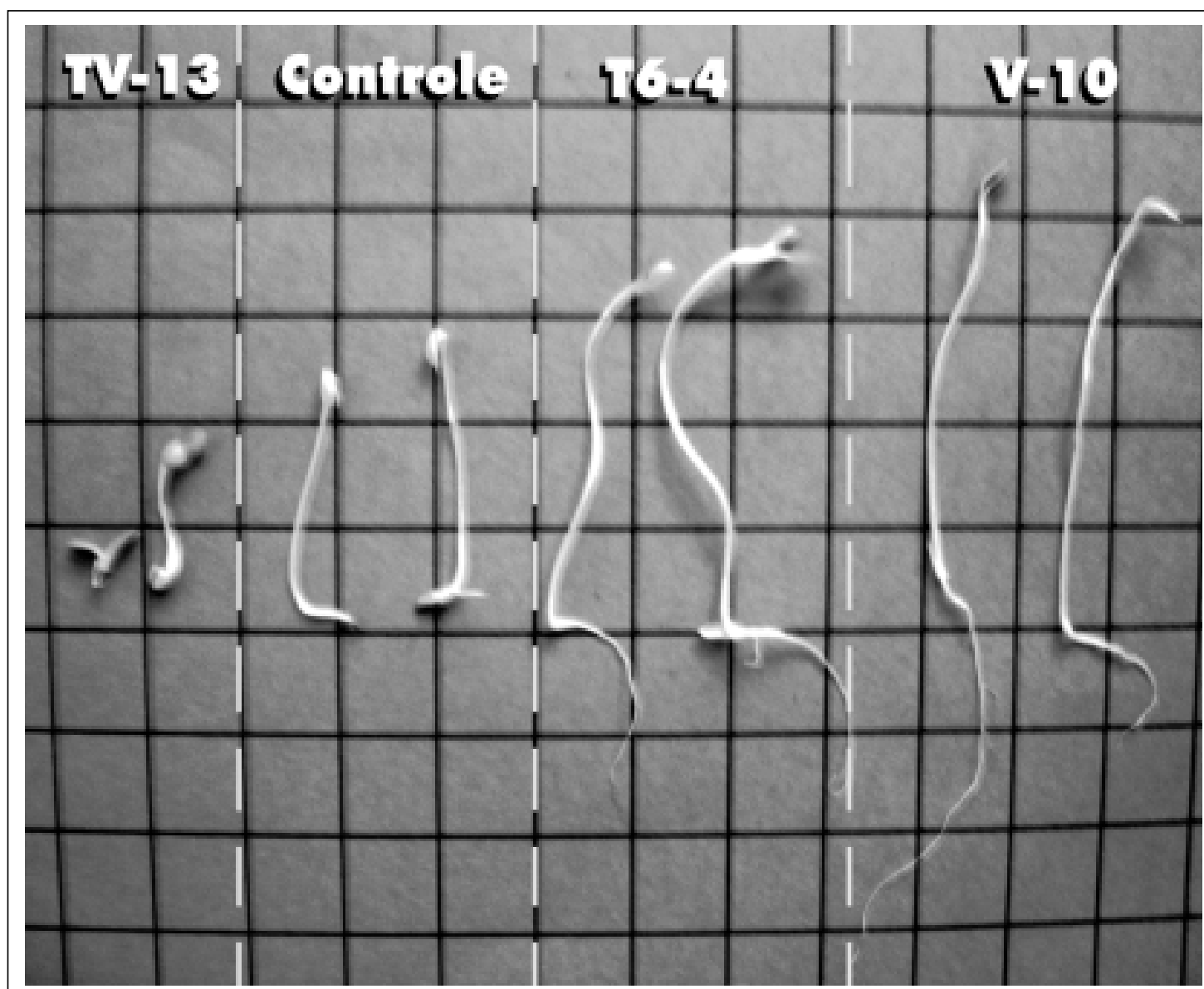

Figura 1 - Desenvolvimento de plântulas de alface inoculadas com três diferentes isolados de rizóbios, em comparação com o controle não-inoculado. 
desenvolvimento inicial das plântulas. Porém a ação deste hormônio depende de outros mecanismos que regulam sua liberação da forma conjugada para livre entre os tecidos de reserva e as demais partes da planta. Em sementes de alface, que dispõem de quantidades menores de substâncias de reserva comparadas a algumas espécies produtoras de grãos, a germinação e o desenvolvimento inicial das plântulas parecem estar mais influenciados pela adição exógena de reguladores de crescimento e por associações com microoganismos. Segundo DINIZ et al. (2006), a inoculação de sementes de alface com Trichoderma viride e a presença de reguladores de crescimento, através de técnicas de peliculização, promovem um aumento na emergência e no índice de velocidade de emergência das plântulas. Já a inoculação com isolados de Bacillus thuringiensis foi capaz de aumentar as taxas de nitrogênio foliar e de matéria seca total em mudas de alface (GOMES et al., 2003).

A produção excessivamente elevada de AIA por TV-13 poderia ser a responsável pelos efeitos nocivos do isolado sobre as sementes de alface, pois é sabido que auxinas em geral, incluindo o AIA, possuem ação herbicida (FARGASOVA, 1994). Porém, apenas a presença de triptofano, independente do AIA exógeno, também pode resultar em forte efeito inibitório sobre a germinação de determinadas sementes, como as de trigo (RAMAIH et al., 2003). Além disso, algum outro metabólito produzido pelo isolado TV-13, que não o AIA, poderia ter sido a causa dos seus efeitos nocivos às sementes de alface. Bactérias produtoras de $\mathrm{HCN}$, por exemplo, podem produzir efeitos deletérios sobre plantas (SCHIPPERS et al., 1990).

Contudo, no experimento 2, a simples presença de triptofano não causou danos às sementes, assim como a presença de TV-13 sem adição de triptofano ao meio (Tabela 3). A germinação de alface foi prejudicada apenas quando houve a presença simultânea do triptofano e do isolado TV-13. Tanto as amostras esterilizadas quanto aquelas em que o isolado permaneceu ativo tiveram um efeito negativo nas sementes de alface, constatado pela ausência de plântulas normais (N\%). A presença da bactéria viva produziu efeito negativo mais acentuado, com reduções significativas também na G\% final e no IVG\%. Nos tratamentos com TV-13 crescido em meio com triptofano, também ocorreu um menor desenvolvimento das plântulas, com redução do comprimento da raiz e da parte aérea.

A menor intensidade dos efeitos negativos, observada no tratamento submetido à esterilização por autoclavagem, mostrou que a interrupção da atividade do isolado TV-13 e da sua produção contínua de AIA proporcionou a recuperação parcial da germinação e do desenvolvimento das plântulas de alface. Embora resistente à autoclavagem, a quantidade inicial de AIA era elevada, podendo ter havido uma redução na sua concentração, provavelmente por fotodegradação (FACHINELLO, 1995). No entanto, essa redução não foi compensada pela produção de mais AIA pela bactéria viva.

Nos tratamentos sem adição de triptofano ao meio, com ou sem o rizóbio, nenhum dos parâmetros analisados foi afetado. Esses resultados indicam que a toxidez foi realmente decorrente da produção excessiva de AIA pelo isolado TV-13 a partir de triptofano e não de um outro metabólito produzido pelo isolado a partir de algum componente do meio de cultura.

No terceiro experimento, a presença de AIA sintético também apresentou um efeito inibitório sobre a germinação das sementes de alface (Tabela 4). No entanto, este efeito só foi significativo sobre o IVG, havendo um retardo da germinação com o aumento das concentrações de AIA. Embora as concentrações mais elevadas também tenham aumentado o número de plântulas com anormalidades, não foram detectadas diferenças significativas entre os tratamentos e o controle. Com isso, constatou-se que as altas concentrações de AIA sintético não reduziram de forma tão acentuada a germinação de alface quanto os

Tabela 3 - Efeito de tratamentos com rizóbio TV-13 sobre a germinação e o desenvolvimento de plântulas de alface.

\begin{tabular}{|c|c|c|c|c|c|}
\hline \multirow{2}{*}{ Tratamento } & \multicolumn{3}{|c|}{ Germinação } & \multicolumn{2}{|c|}{ Comprimento } \\
\hline & Final & Normais & IVG & Parte aérea & Raiz \\
\hline & \multicolumn{3}{|c|}{----------------- \% $\%$-----------------' } & \multicolumn{2}{|c|}{----------- $(\mathrm{cm})$----------. } \\
\hline Água estéril & $94,0 \mathrm{a}$ & 87,0 a & $15,58 \mathrm{ab}$ & $1,45 \mathrm{a}$ & $0,90 \mathrm{a}$ \\
\hline LM+triptofano (trip) & $98,5 \mathrm{a}$ & 98,0 a & $16,42 \mathrm{a}$ & $1,99 \mathrm{a}$ & $0,95 \mathrm{a}$ \\
\hline $\mathrm{LM}+\mathrm{TV}-13$ & $97,0 \mathrm{a}$ & 96,0 a & $16,11 \mathrm{ab}$ & $1,62 \mathrm{a}$ & $0,39 \mathrm{~b}$ \\
\hline $\mathrm{LM}+$ trip$+\mathrm{TV}-13$ & $85,5 \mathrm{~b}$ & $0,0 \mathrm{~b}$ & $13,32 \mathrm{c}$ & $0,21 \mathrm{~b}$ & $0,13 \mathrm{c}$ \\
\hline $\mathrm{LM}+$ trip $+\mathrm{TV}-13+$ autoclavavagem & $92,5 \mathrm{a}$ & $0,0 \mathrm{~b}$ & $15,03 \mathrm{~b}$ & $0,31 \mathrm{~b}$ & $0,16 \mathrm{c}$ \\
\hline
\end{tabular}

Médias seguidas de mesma letra dentro das colunas não diferem significativamente entre si pelo teste de Tukey $(\mathrm{P}>0,05)$.

Ciência Rural, v.38, n.3, mai-jun, 2008. 
Tabela 4 - Efeito de diferentes concentrações de AIA sintético sobre a germinação de sementes de alface.

\begin{tabular}{lccc}
\hline & & Germinação \\
\cline { 2 - 4 } & Final $\left(\mu \mathrm{g} \mathrm{mL}^{-1}\right)$ & Normais & IVG \\
\cline { 2 - 4 } 0 & $91,0 \mathrm{a}$ & $70,5 \mathrm{a}$ & $9,33 \mathrm{a}$ \\
2,5 & $95,0 \mathrm{a}$ & $72,5 \mathrm{a}$ & $\mathrm{ab}$ \\
25 & $87,5 \mathrm{a}$ & $65,0 \mathrm{a}$ & $8,90 \mathrm{~b}$ \\
50 & $89,0 \mathrm{a}$ & $60,0 \mathrm{a}$ & $8,67 \mathrm{c}$ \\
100 & $93,0 \mathrm{a}$ & $60,0 \mathrm{a}$ & $6,50 \mathrm{c}$ \\
\hline
\end{tabular}

Médias seguidas de mesma letra dentro das colunas não diferem significativamente entre si pelo teste de Tukey $(\mathrm{P}>0,05)$.

tratamentos com culturas ativas de TV-13 crescido em meio com triptofano, aplicados nos experimentos 1 e 2 . Neste caso, também a ausência da bactéria poderia ser um fator atenuante sobre os efeitos deletérios das altas concentrações deste fitormônio. Como o AIA não é fotoestável (FACHINELLO, 1995), os resultados obtidos poderiam ser explicados pela fotodegradação desse fitormônio, uma vez que os testes foram conduzidos na presença de luz constante. Assim, mesmo as altas concentrações deixariam de ser nocivas ao longo do teste, causando apenas um retardo na germinação, o que foi evidenciado nesse experimento pela redução do índice $\mathrm{IVG} \%$.

\section{CONCLUSÕES}

Os isolados de Bradyrhizobium sp. T6-12; V10; T6-4 e C3 produziram quantidades baixas de AIA $\left(1,2\right.$ a $\left.3,3 \mu \mathrm{g} \mathrm{mL}^{-1}\right)$ e elevaram alguns dos parâmetros de germinação e de crescimento das plântulas de alface em relação ao tratamento sem inoculação com rizóbios.

O isolado TV-13, na presença de triptofano, tem uma produção elevada de $\operatorname{AIA}\left(171,1 \mu \mathrm{g} \mathrm{mL}^{-1}\right)$ que foi deletéria às plântulas de alface, provocando perdas no vigor das sementes e na formação de plântulas anormais. Os efeitos negativos da inoculação com TV13 estão associados apenas ao AIA, pois são dependentes do triptofano disponível no meio de cultura.

Com base nos resultados obtidos neste trabalho, recomenda-se a inoculação de sementes de alface com rizóbios que produzem baixas quantidades de AIA.

\section{REFERÊNCIAS}

AHMAD, F. et al. Indole acetic acid production by the indigenous isolates of Azotobacter and fluorescent Pseudomonas in the presence and absence of tryptophan. Turkish Journal of Biology, Ankara, v.29, n.1, p.29-34, 2005.
ASGHAR, H.N. et al. Relationship between in vitro production of auxins by rhizobacteria and their growth-promoting activities in Brassica juncea L. Biology and Fertility of Soils, Berlin, v.35, n.4, p.231-237, 2002

BARAZANI, O.; FRIEDMAN, J. Is IAA the major root growth factor secreted from plant-growth-mediating bacteria? Journal of Chemical Ecology, Dordrecht, v.25, n.10, p.2397-2406, 1999.

BIALEK, K.; COHEN, J. Amide-linked indoleacetic acid conjugates may control levels of indoleacetic in germinating seedlings of Phaseolus vulgaris. Plant Physiology, Rockville, v.100, n.4, p.2002-2007, 1992.

BIALEK, K. et al. Auxin biosynthesis during seed germination in Phaseolus vulgaris. Plant Physiology, Rockville, v.100, n.1, p.509-517, 1992

BISWAS, J.C. et al. Rhizobial inoculation influences seedling vigor and yield of rice. Agronomy Journal, Madison, v.92, n.5, p.880-886, 2000.

DINIZ, K.A. et al. Incorporação de microrganismos, aminoácidos, micronutrientes e reguladores de crescimento em sementes de alface pela técnica de peliculização. Revista Brasileira de Sementes, Pelotas, v.28, n.3, p.37-43, 2006.

FACHINELLO, J.C et al. Propagação de plantas frutíferas de clima temperado. 2.ed. Pelotas: Ufpel, 1995. 178p.

FARGASOVA, A. Comparative study of plant growth hormone (herbicide) toxicity in various biological subjects. Ecotoxicology and Environmental Safety, Zabrze, v.29, n.3, p.359-364, 1994

GOMES, A.M.A. et al. Isolamento, seleção de bactérias e efeito de Bacillus spp. na produção de mudas orgânicas de alface. Horticultura Brasileira, Brasília, v.21, n.4, p.699-703, 2003

HAFEEZ, F.Y. et al. Rhizobial inoculation improves seedling emergence, nutrient uptake and growth of cotton. Australian Journal of Experimental Agriculture, Collingwood, v.44, n.6, p.617-622, 2004

HARPER, J.L. Population biology of plants. London: Academic, 1977. 892p.

ISTA - International rules for seed testing. Seed Science and Technology. Zurich, 1996. 335p.

Ciência Rural, v.38, n.3, mai-jun, 2008. 
MAGUIRE, J.D. Speed of germination - and in selection for seedling emergence and vigor. Crop Science, Madison, v.2, n.2, p.176-177,1962.

NOEL, T.C. et al. Rhizobium leguminosarum as a plant growthpromoting rhizobacterium: direct growth promotion of canola and lettuce. Canadian Journal of Microbiology, Ottawa, v.42, n.3, p.279-283, 1996.

RAMAIH, S. et al. Relationship of indoleacetic acid and tryptophan to dormancy and preharvest sprouting of wheat.
Functional Plant Biology, Victoria, v.30, n.9, p.939-945, 2003.

SCHIPPERS, B. et al. Beneficial and deleterious effects of HCN-producing pseudomonads on rhizosphere interactions. Plant and Soil, Dordrecht, v.129, n.1, p.75-83, 1990.

SOTTERO, A.N. et al. Rizobactérias e alface: colonização rizosférica, promoção de crescimento e controle biológico. Revista Brasileira de Ciência do Solo, Viçosa, v.30, n.2, p.225-234, 2006. 